María Sampedro Mella*

\title{
Entre el ofrecimiento y la orden: la reproducción de peticiones en secuencias de estilo directo en entrevistas semidirigidas
}

\section{Between command and offer: the reproduction of requests in direct speech in sociolinguist interviews}

https://doi.org/10.1515/soprag-2021-0001

Publicado en línea Mayo 31, 2021

Resumen: La petición es un acto de habla que ha sido ampliamente analizado en la bibliografía del español, especialmente a partir de cuestionarios de uso. En este artículo procedemos a su estudio desde una nueva perspectiva: la reproducción de la petición en el discurso directo. Para llevar a cabo la investigación, se ha recopilado un subcorpus de 112 enunciados de estilo directo que contienen peticiones, procedentes de una muestra de corpus orales de entrevistas semidirigidas del español centro-norte peninsular. Se han distinguido dos tipos de peticiones según su contexto de producción original: por un lado, en situaciones transaccionales y, por otro, en interacciones de proximidad social. A continuación, se han clasificado las estrategias utilizadas en la expresión de este acto de habla entre las más directivas, que hacen que la petición se asemeje a la orden, y las más indirectas, que la aproximan al ofrecimiento. A partir de los datos recopilados, se analiza si se producen variaciones en la expresión de este acto entre ambos tipos de situaciones, y si el contexto comunicativo en el que se reproduce el discurso -la entrevista semidirigida- influye en la expresión, por el interés de los hablantes en proyectar una imagen social de sí mismos más cuidada y formal, acorde a las nuevas circunstancias contextuales.

\footnotetext{
*Corresponding author: María Sampedro Mella, Facultad de Filología, Departamento de Lengua y Literatura Españolas, Teoría de la Literatura y Lingüística General, Universidade de Santiago de Compostela, Santiago de Compostela, Spain, E-mail: maria.sampedro.mella@usc.es. https:// orcid.org/0000-0002-7039-1954
}

Ә Open Access. ๑ 2021 María Sampedro Mella, published by De Gruyter. (G) Br-Nc-ND This work is licensed under the Creative Commons Attribution-NonCommercial-NoDerivatives 4.0 International License. 
Palabras clave: actos de habla, petición, imagen social, discurso directo, entrevista semidirigida

Abstract: Request is a speech act which has been thoroughly researched in Spanish bibliography, especially through linguistic surveys. In this paper, request is analyzed from a new viewpoint: the reproduction of requests in direct speech. In order to undertake this research, a subcorpus made of 112 examples of direct style, which contain requests, has been compiled from a selection of corpora from sociolinguistic interviews in north-central Peninsular Spanish. Two kinds of requests have been distinguished according to their original context: on the one hand, requests produced in service encounters and, on the other hand, in interactions with close individuals. Then, the linguistic strategies used in the expression of this speech act have been classified in those more direct, which make requests similar to orders, and those more indirect, which bring them closer to offers. Based on the compiled data, the possible variations in the expression of this speech act are analyzed in the two linguistic exchanges. Furthermore, the analysis explores the possible influence of the communicative context -the sociolinguistic interview- in the verbal expression, due to the interest of the speakers to show a more formal, and appropriate for the new context, face.

Keywords: speech acts, request, direct speech, face, sociolinguistic interview

\section{Introducción: la petición}

Los actos de habla (Searle, 1969) son las unidades mínimas de comunicación lingüística con las que se lleva a cabo una acción determinada y constituyen el objeto de estudio de la pragmática. En este trabajo se analiza la petición, perteneciente a los denominados actos directivos (Searle, 1969), en el español centro-norte peninsular. La petición se define como un acto en el que "el hablante trata de hacer que el oyente haga algo en beneficio del propio hablante" (Alba de Diego, 1994, p. 416). Se opone, por tanto, al ofrecimiento, cuyo funcionamiento consiste en la utilización de una acción llevada a cabo por el interlocutor en beneficio del emisor (Escandell Vidal, 1999), y a la orden, o mandato, que implica que el emisor se sitúa en una posición de poder con respecto al receptor, para obligarlo a realizar la acción requerida (Haverkate, 1994). Esta definición general de la petición no resulta, sin embargo, operativa en los intercambios transaccionales ('service encounters'), en los que la realización del acto tiene como fin último la adquisición de un bien o un servicio y, por ello, el beneficio recae, a priori, en los dos participantes: en el vendedor, por la ganancia derivada de una venta, y en el consumidor, por su compra. 
En los últimos treinta años, la petición ha sido objeto de investigación en numerosas lenguas, entre ellas el español en sus distintas variedades, ${ }^{1} \mathrm{y}$ se han propuesto diferentes aproximaciones, tanto para la recopilación de las muestras como para su estudio. La mayoría de los trabajos disponibles están basados en la metodología DCT (Discourse Completion Test), un cuestionario que intenta reproducir las circunstancias de la lengua oral, al que generalmente se responde por escrito y que, con frecuencia, adopta un modelo de análisis que parte de la propuesta de Blum-Kulka (1989). Esta autora distingue hasta nueve formas posibles de expresión de la petición, que Félix-Brasdefer (2005), en un estudio sobre este acto en el español mexicano, reduce a tres: las peticiones directas ('direct'), indirectas convencionales ('conventional indirectness') e indirectas no convencionales ('non-contentional indirectness').

Desde los trabajos clásicos de cortesía (Brown y Levinson, 1987; Haverkate, 1994), la petición se ha caracterizado como un acto impositivo y no cortés, debido a su naturaleza amenazante para la imagen negativa del receptor y la imagen positiva del emisor, pues este puede sentirse rechazado. En consecuencia, en su realización, resulta necesario recurrir a estrategias corteses indirectas o de reparación y mitigación, para atenuar la fuerza impositiva del acto y evitar así la posible amenaza al interlocutor. No obstante, en el caso del español peninsular, algunos autores sostienen que la sociedad española, por su vinculación con las culturas de acercamiento (Albelda y Briz, 2010; Grupo CRIT 2003, 2006), emplea el imperativo y otras estrategias de carácter directivo en la expresión de este acto (Haverkate, 1994; Hernández Flores, 2002; Siebold, 2006). Por el contrario, en otros trabajos basados en la metodología DCT, se observa una tendencia al uso de estrategias indirectas (Lorenzo Díaz, 2016; Querol Bataller, 2016; Sampedro Mella, 2019).

En este trabajo procedemos al estudio de la petición desde una perspectiva novedosa: el estilo directo reproducido en entrevistas semidirigidas. Se ha recopilado un subcorpus de un total de 112 peticiones de una muestra de corpus de entrevistas semidirigidas del español centro-norte peninsular. Estas peticiones fueron formuladas originalmente en el ámbito familiar -con amigos, familiares, personas cercanas, etc.- y en el transaccional -en establecimientos públicos, como cafeterías, panaderías, joyerías, bancos, etc. - , y han sido reproducidas a través del discurso directo de los entrevistados en las entrevistas semidirigidas. El análisis se centra, por un lado, en la clasificación de los procedimientos registrados en la expresión de las peticiones, según su grado de dirección (directness),

1 Solo por mencionar algunos estudios dentro de la variedad del presente estudio, el español peninsular: Alba de Diego (1994), Siebold (2006), Lorenzo Díaz (2016), Querol Bataller (2016), Schrott (2017), Sampedro Mella (2019), entre otros. 
de los más directivos a los indirectos, a partir de las propuestas de algunos estudios sobre este acto (Alba de Diego, 1994; Escandell Vidal, 2006; Félix-Brasdefer, 2005; Haverkate, 1994). Por otro lado, al estar ante muestras textuales de estilo directo procedentes de entrevistas semidirigidas, se tienen en cuenta las posibles variaciones en el discurso de los hablantes para adaptar su mensaje original al nuevo contexto comunicativo, más formal, y construir una imagen de afiliación (Bravo, 1999, 2008; Hernández Flores, 1999, 2006) satisfactoria y acorde a las características de la entrevista.

\section{Marco teórico}

\subsection{Cortesía y actividades de imagen}

La cortesía verbal es el "conjunto de normas sociales establecidas por cada sociedad, que regulan el comportamiento adecuado de sus miembros, prohibiendo algunas formas de conducta y favoreciendo otras" (Escandell Vidal, 2006, p. 136). La cortesía está considerada como un fenómeno universal, cuyas formas de aplicación varían entre unas sociedades y otras, y propio del comportamiento humano (Brown y Levinson, 1987; Goffman, 1967). A partir del concepto de imagen social (face), postulado originalmente por Goffman, como el valor social positivo que un individuo reclama para sí a través de la valoración de otros en un contacto particular (Goffman, 1967, p. 5), las personas han de llevar a cabo trabajos o actividades de imagen (face work) en sus relaciones sociales, a fin de conseguir una imagen que se ajuste a sus expectativas y a las de sus interlocutores en su entorno social. Para ello, deben acatar diferentes normas, mediante la aplicación de los principios de cortesía presentes en su comunidad.

A esta noción seminal de imagen social, Brown y Levinson (1987, p. 13) le asociaron años después las vertientes negativa y positiva: "the desire to be unimpeded in one's actions (negative face), and the desire (in some respects) to be approved (positive face)". A cada una de estas dos imágenes le corresponde también un tipo de cortesía: la cortesía negativa y la cortesía positiva. La primera se emplea para minimizar el impacto del enunciado expresado al interlocutor: "is essentially avoidance-based, and realizations of negative-politeness strategies consist in assurances that the speaker recognizes and respects the addressee's negative-face wants and will not (or will only minimally)" (Brown y Levinson, 1987: 69). La cortesía positiva, por su parte, se dirige a la imagen positiva del receptor, con el fin de satisfacer sus deseos de proyección de imagen, hacer que se sienta bien, cómodo, positivamente valorado, etc. 
Bravo (1999, 2008) ha reinterpretado el concepto de imagen social como una categoría básica y vacía que los hablantes completan de acuerdo con los principios de la sociedad en la que se encuentran. Esta autora distingue así una doble vertiente dentro de la imagen de cada sujeto: una imagen de autonomía, que representa la visión que el propio individuo posee de sí mismo como alguien con contorno propio dentro del grupo, y una imagen de afiliación, correspondiente a la identificación del sujeto con el grupo social, para poder lograr su aceptación (Bravo, 1999, 2008; Hernández Flores, 1999, 2006). De ese modo, la actuación del individuo no responde únicamente a la proyección interesada de sus propios deseos de imagen, sino que también debe satisfacer las expectativas del otro para alcanzar la aceptación y la integración social.

Si en la realidad cotidiana las imágenes de afiliación y de autonomía se construyen a través de las acciones y de la comunicación que regulan las actividades diarias, en la entrevista semidirigida, por sus características discursivas y la relación que se establece entre los interlocutores, se produce una readaptación de las actividades de imagen del entrevistado, para salvaguardar su autonomía y su afiliación. Esto se pone de manifiesto en la exposición de un discurso conveniente en su forma y contenido, y que cumpla con el propósito de presentar una imagen deseable dentro de los límites regulados por el evento comunicativo. En esta investigación el objeto de estudio es, a su vez, el discurso directo reproducido en la entrevista semidirigida, por lo que podría existir un conflicto entre la reproducción literal del mensaje y la adaptación al nuevo contexto, como se expone en 2.2.

\subsection{El discurso directo en la entrevista semidirigida}

La entrevista semidirigida es un método diseñado por William Labov, en los años sesenta del pasado siglo, con el propósito de recoger muestras de lengua reales propias del estilo espontáneo o vernáculo, para el estudio del uso y del cambio lingüístico (Labov, 1966). La entrevista semidirigida no existe, por tanto, como género discursivo único, sino que se trata de un género híbrido entre la conversación espontánea y la entrevista prototípica, que se regula por una serie de normas discursivas y también sociales: los roles de los participantes están determinados con anterioridad al encuentro, la toma de turno está predeterminada y el registro empleado acostumbra a ser semiformal, debido a la ausencia de total naturalidad de este género y a la presencia explícita del instrumento de grabación, junto con la falta de conocimiento, en muchos casos, entre el entrevistador y el entrevistado (cf. Fernández Sanmartín, García Salido, Recalde y Vázquez Rozas, 2008). 
Dado que el objetivo de la entrevista semidirigida es la recopilación de muestras lingüísticas, los entrevistadores procuran estimular la participación de los entrevistados. Con este fin, en algunos casos (v.g. PRESEEA-Valencia) se sigue un guion preestablecido de antemano, mientras que en otros (v.g. ESLORA) se acomoda la entrevista a la personalidad de cada entrevistado, mediante la introducción de temas que sean de su agrado y que surjan al hilo del propio intercambio. Por este motivo, es habitual encontrar narraciones y descripciones en los testimonios de los entrevistados que contienen construcciones en estilo directo, pues la incorporación de este tipo de secuencias supone una manera de vivificar el discurso de los hablantes (Estévez-Rionegro, 2017, p. 47), aunque su objetivo final sea la reproducción literal de un mensaje transmitido con anterioridad: "Se denomina discurso directo el que reproduce palabras pronunciadas de forma literal, así como pensamientos transcritos en la misma forma en que se originan (...) Requiere por lo general la presencia de un verbo introductor como decir, explicar, manifestar, opinar, repetir o responder, entre otros” (RAE y ASALE, 2009, pp. 3273 y ss.).

En el discurso directo concurren dos discursos pertenecientes a dos voces diferentes en una sola: el de un hablante que toma las palabras de sí mismo o de otro y las reproduce literalmente en su propio discurso, conservando sus elementos deícticos y manteniendo intacto el texto original. Algunos autores defienden la literalidad del discurso transmitido en la cita, aun admitiendo que "[n]o importa que en la cita se reproduzcan palabras no emitidas realmente. Todo discurso citado, sea real o imaginario, supone necesariamente la reconstrucción de su situación de enunciación correspondiente" (Maldonado González, 1991, p. 17). Otros, en cambio, se oponen a esta supuesta exactitud: "El discurso directo es a la vez un mecanismo de reproducción y de atribución de actos de habla por medio del ensamblaje de un producto en otro producto (de un enunciado en otro), y la literalidad no es más que una ficción discursiva de la reproducción (...)” (Méndez García de Paredes, 2000, p. 156). Esto es debido a que el discurso directo representa la idea que el hablante tiene del mensaje emitido por otro y que intenta reproducir, por lo que su empleo no asegura la literalidad del contenido presentado (Estévez-Rionegro, 2017, p. 86). ${ }^{2}$

El análisis de un fenómeno pragmático como la expresión de las peticiones a través del discurso directo reproducido en entrevistas semidirigidas nos ofrece una doble perspectiva: por una parte, nos conduce a la emisión literal del mensaje,

2 Como señala Gallucci (2012, p. 216), los estudios sobre el discurso referido en español se han centrado, fundamentalmente, en el análisis de textos escritos del ámbito académico, periodístico o literario. Por otro lado, las investigaciones disponibles sobre la lengua oral se han interesado por la estructura sintáctica de la construcción, la semántica de los verbos introductores o las funciones pragmáticas de la cita reproducida en el discurso, prescindiendo de la cuestión de la literalidad del discurso oral reproducido. 
proporcionándonos datos acerca de la realización de este acto de habla en su contexto de producción natural; por otra parte, aunque no podamos contar con el discurso original para conocer las variaciones que aparecen en su paso al estilo directo, nos muestra la posible reinterpretación que los hablantes hacen del hecho lingüístico en su reproducción para adaptarlo a esta nueva situación comunicativa: el empleo de un lenguaje más elaborado y de un registro más formal y cuidado que en la conversación espontánea, o un incremento en el número de procedimientos de atenuación, que permitan suavizar el carácter impositivo de ciertos actos de habla potencialmente amenazantes, como es el caso de las peticiones.

\section{Aspectos metodológicos}

Para llevar a cabo este trabajo, partimos del análisis de un subcorpus de peticiones formuladas en el discurso directo, que ha sido recopilado a partir de los siguientes corpus de entrevistas semidirigidas:

- Corpus de habla culta de Salamanca (CHCS). Nivel superior (Fernández Juncal, 2005)

- Corpus para el estudio del español oral (ESLORA) de Santiago de Compostela. Niveles superior y medio.

- Corpus Sociolingüístico de Castellón de la Plana y su área metropolitana (CSCP). Niveles superior, medio y primario (Blas Arroyo et al., 2009).

- Proyecto para el estudio del español de España y América (PRESEEA). Alcalá de Henares. Niveles superior, medio y primario (Moreno Fernández et al., 2002).

- Proyecto para el estudio del español de España y América (PRESEEA) Valencia. Nivel primario (Gómez Molina, 2007).

La elección de estos corpus responde a varias razones: en primer lugar, contienen muestras recientes de lengua oral (han sido publicados después del año 2000) de la realidad lingüística de una zona concreta: el español centro-norte peninsular. Asimismo, se basan en una muestra sistemática y sociolingüísticamente representativa, seleccionada en función de criterios geográficos y sociales concretos, a saber, el tiempo de residencia de los hablantes en una localidad determinada, su sexo, edad y nivel sociocultural, distribuido en tres niveles: sujetos con estudios universitarios o de enseñanza superior, con estudios primarios y secundarios completos, y carentes de estudios o solo con la enseñanza primaria.

Todos ellos son corpus discursivos orales de acceso completo al texto, ya que no es posible recuperar los enunciados que contienen peticiones a través de los buscadores que ofrecen los corpus. Por otro lado, aunque en algunos de ellos se 
identifican los fragmentos de discurso directo mediante el etiquetado (ESLORA) o cursivas (PRESEEA), estas demarcaciones son, en ocasiones, imprecisas y se presentan sin el contexto suficiente para poder interpretar correctamente las secuencias. En consecuencia, para este trabajo ha sido imprescindible llevar a cabo una lectura y una revisión íntegras de cada una de las entrevistas que conforman estos corpus; una vez examinadas, se ha procedido a la identificación de las secuencias de cita que contienen peticiones en su formulación, lo que ha dado lugar an un subcorpus constituido por 112 enunciados: 28 peticiones formuladas originalmente en intercambios transaccionales, con el fin de adquirir un producto o un servicio en un establecimiento público (una joyería, una carnicería, un banco...), y 84 en el ámbito familiar, i.e., con amigos, vecinos, familiares, conocidos, etc.

\section{Resultados}

\subsection{Resultados generales}

Siguiendo el grado de dirección, las estrategias pragmalingüísticas documentadas en la expresión de la petición se han organizado según su carácter más o menos directivo. De acuerdo con Alba de Diego (1994), Haverkate (1994), Félix-Brasdefer (2005) y Escandell Vidal (2006), en los procedimientos directos se han incluido el imperativo (dame una barra de pan), las construcciones volitivas (quiero una barra de pan) y sin marcas de atenuación (una barra de pan). Por otra parte, dentro de los procedimientos indirectos se han incluido las secuencias interrogativas -con o sin atenuadores (¿tienes/tendrías pan?)- y las afirmativas que contienen elementos de mitigación y que, por tanto, permiten disminuir la fuerza ilocutiva del enunciado (Albelda y Briz, 2010, p. 245): formas verbales en distintos tiempos (querría/quería) quisiera una barra de pan), perífrasis con el verbo poder (¿puedes/podrías darme una barra de pan?), construcciones con otros procedimientos de atenuación (perdone/a, por favor...), así como peticiones indirectas no convencionales (mira, es que estaba buscando...) (cf. Félix-Brasdefer, 2005; Escandell Vidal, 2006):

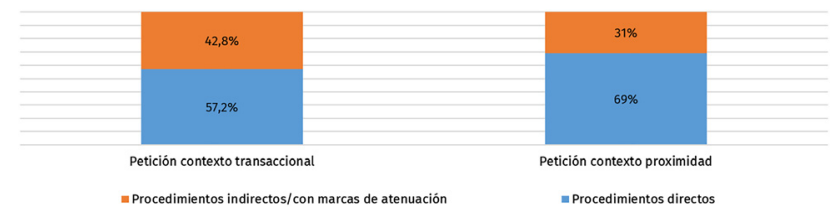

Gráfica 1: Clasificación de los procedimientos empleados en la expresión de la petición en contextos transaccionales y de proximidad. 
Los datos de la primera gráfica muestran unos resultados similares en la realización del acto de petición. Así, destaca el uso de estrategias directas, con un $57,2 \%$ en un intercambio transaccional y un 69\% en una situación de familiaridad, mientras que los porcentajes correspondientes a los procedimientos indirectos se sitúan entre el 31\%, en los contextos de proximidad, y el 42,8\%, en las transacciones. Este incremento en los intercambios transaccionales, que examinamos en los siguientes apartados, podría obedecer a diferentes razones, como a la falta de conocimiento entre los interlocutores, a la formalidad de algunas de las situaciones o al coste-beneficio del acto para el receptor-vendedor, según la petición realizada.

Veamos las estrategias pragmalingüísticas utilizadas específicamente en la expresión de la petición en cada uno de estos dos contextos:

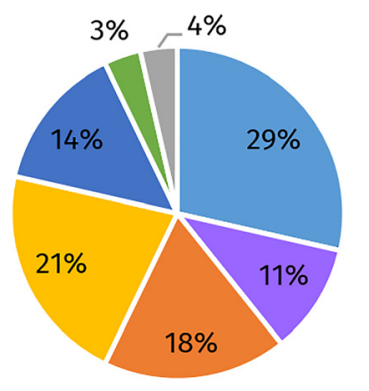

$$
\begin{aligned}
& \text { - Imperativo } \\
& \text { - Enunciativa volitiva } \\
& \text { - Enunciativa directa } \\
& \text { - Enunciativa atenuada } \\
& \text { - Interrog. directa } \\
& \text { - Interrog. atenuada } \\
& \text { - Peticiones indirectas }
\end{aligned}
$$

Gráfica 2: Formulación de la petición en un contexto transaccional (del cliente al vendedor).

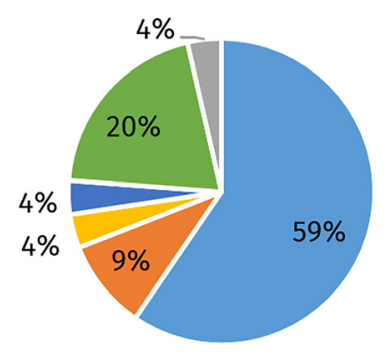

$$
\begin{aligned}
& \square \text { Imperativo } \\
& \square \text { Enunciativa directa } \\
& \square \text { Enunciativa atenuada } \\
& \square \text { Interrog. directa } \\
& \square \text { Interrog. atenuada } \\
& \text { घ Peticiones indirectas }
\end{aligned}
$$

Gráfica 3: Formulación de la petición en una situación de proximidad.

Si bien, en conjunto, las estrategias que aparecen en las peticiones realizadas en el ámbito transaccional y familiar son similares en cuanto a su grado de dirección (cf. gráfica 1), los datos de las gráficas 2 y 3 presentan algunas variaciones en los recursos seleccionados. Así, el imperativo es la forma más utilizada, pero los 
porcentajes de uso difieren en ambos contextos: un 29\% en transacciones vs. un $59 \%$ en el ámbito familiar. Por otro lado, en los intercambios transaccionales también es frecuente la expresión de la petición a través de una secuencia enunciativa directa (18\%) o atenuada (21\%), así como la interrogativa directa (14\%). En cambio, en el ámbito familiar, predomina la interrogativa atenuada (20\%), que casi no se documenta en los contextos transaccionales (3\%), seguida de la enunciativa directa (9\%); los restantes recursos apenas suponen, en conjunto, un $12 \%$ del total registrado en las muestras correspondientes a las situaciones de proximidad. Cabe mencionar que, en los intercambios transaccionales, aparecen oraciones enunciativas volitivas introducidas por el verbo querer (11\%) que no se documentan en la esfera familiar, ${ }^{3}$ y que las peticiones indirectas no convencionales apenas se emplean en ninguno de los dos ámbitos (4\% en cada uno).

Destaca, por consiguiente, la utilización del imperativo en ambos tipos de petición, que Querol Bataller (2016) correlaciona con situaciones de igualdad en términos de poder y distancia social, o restringido a contextos de proximidad. También sorprende el uso mayoritario de estrategias directas, pues, como anticipamos, las investigaciones del español peninsular basadas en la metodología DCT (Lorenzo Díaz, 2016; Sampedro Mella, 2019) registran una mayor incidencia de procedimientos indirectos para realizar el acto de la petición, en especial en los intercambios transaccionales.

En este análisis se esperaba documentar un uso similar, por tratarse de secuencias en estilo directo reproducidas en entrevistas semidirigidas. Así, los entrevistados podrían tener interés en construir una imagen afiliativa más atenuada o formal, para adecuarse a las características de esta situación comunicativa, de mayor formalidad que la conversación espontánea, por la falta de total naturalidad del encuentro, el hecho de estar siendo grabados, de no conocer al entrevistador (en muchos casos), etc. (cf. Fernández Sanmartín et al. 2008). Sin embargo, los resultados indican que los hablantes aceptan el empleo de una formulación directa como normativo o adecuado, pues no parecen sentir que su imagen afiliativa esté en peligro y, por ello, no necesitan recurrir a la atenuación para adaptar su discurso al contexto de la entrevista semidirigida. En otras palabras, no hay indicios de conflicto entre la imagen de autonomía, a la que se vincula el uso de formas directas en la expresión de la petición en el contexto original de producción, y la imagen de afiliación, que busca la aceptación del interlocutorentrevistador en el contexto en el que se reproduce el discurso, i.e., en la entrevista semidirigida.

3 Con una única excepción que explicamos en 4.2. 


\subsection{Entre la petición y la orden}

En este apartado procedemos al estudio de las peticiones que presentan una formulación directa, lo que hace que, en ocasiones, se puedan confundir con una orden, debido a su nivel de imposición. ${ }^{4}$ Veamos, en primer lugar, algunos ejemplos expresados a través del imperativo en contextos transaccionales (1-3) y familiares (4-9):

(1) yo voy ahí y ponme tre(i)nta euros/ ponme tre(i)nta euros ${ }^{5}$ (VAL01012HB02)

(2) y allí ya venga ponme una copa de coñac (PRESEEA-Alcalá med. E. 31)

(3) desde la puerta dame una barra (ESLORA med. SCOM_M12_020)

(4) siempre me dice hazme unos espaguetis (VAL02311HB06)

(5) y le dijo a mi abue- a mi madre abuela no vendas la casa déjamela a mí (PRESEEA-Alcalá sup. E. 17)

(6) le digoo a mi hijo ee esta- haz tú la cama (VAL01313MC03)

(7) dice la niña ayer jmamá hazme la cama que no me da tiempo! (PRESEEA-Alcalá prim. E. 41)

(8) decía llama si tienes ganas (ESLORA med. SCOM_H22_026)

(9) pues daba al timbre oye// Pepe bájate que estorba el coche (PRESEEA-Alcalá prim. E. 37)

Los ejemplos (1) a (3), enunciados originalmente en intercambios transaccionales, aparecen expresados mediante el modo imperativo y carecen de estrategias de atenuación. Así, por contener peticiones pequeñas y encaminadas a la adquisición de un producto propio del establecimiento, concretamente, una gasolinera (1), un bar (2) y una panadería (3), ${ }^{6}$ no suponen, a priori, una amenaza potencial para el vendedor.

\footnotetext{
4 Si bien ambos actos tienen en común la demanda de una acción del emisor al receptor, difieren en el carácter obligatorio u opcional de llevar a cabo dicha acción: en la orden, el hablante se sitúa en una posición de poder con respecto al interlocutor, por lo que se espera de este el cumplimiento de la acción, en tanto que, en la petición, el receptor cuenta con libertad de actuación para realizar o no la acción requerida. En consecuencia, en el nivel pragmalingüístico, pueden aparecer variaciones en el lenguaje: el uso de procedimientos más directivos en el caso de la orden, frente al empleo de estrategias atenuantes en la petición, para persuadir al receptor.

5 Con el fin de homogeneizar la presentación de ejemplos procedentes de distintos corpus, se han suprimido las etiquetas y se ha uniformado la representación de las pausas, que aparecen marcadas mediante distintos procedimientos formales (etiquetas, barras, comas, etc.), a través de barras.

6 La información relativa a los establecimientos donde se realizaron originalmente las peticiones se ha obtenido a partir de la lectura completa de los corpus.
} 
Las peticiones (4) a (9), formuladas en el ámbito familiar, pueden aparecer sin marcas de atenuación, como en (4), que reproduce una petición de bajo coste de una mujer a su marido, o en (5), de mayor coste y nivel impositivo, en la que el nieto le pide directamente a la abuela que le deje a él la casa. La petición (6) se asemeja a una orden, tanto por su formulación, a través del imperativo, como por su situación en términos de poder (de una madre a su hijo). Por el contrario, la misma petición (7) en la situación contraria (de una hija a su madre) presenta procedimientos acompañantes (Calsamiglia y Tusón, 2007), es decir, expresiones añadidas que anuncian o preparan un acto que puede amenazar la imagen social del receptor, como una justificación para aclarar el motivo por el que la emisora debe realizar el acto (que no me da tiempo). Este tipo de elementos acompañantes, que también se encuentra en otras peticiones similares (si tienes ganas, que estorba el coche), permite atenuar la fuerza ilocutiva del imperativo y la imposición que conlleva la petición, destacando la libertad de actuación con la que cuenta el destinatario, frente a un acto como el de la orden.

Como se ha anticipado, los estudios sobre la petición en español no llegan a resultados concluyentes en cuanto al uso del imperativo en la realización de este acto de habla: algunos autores correlacionan la sociedad española con el empleo de este modo verbal en la expresión de la petición (Haverkate, 1994; Siebold, 2006), por su conexión con las llamadas “culturas de acercamiento” (Albelda y Briz, 2010; Grupo CRIT 2003, 2006) y por el "nivel de confianza” (Bravo, 1999; Hernández Flores, 1999, 2006) implicado en las relaciones personales. En cambio, en otras investigaciones se observa que el uso del imperativo está limitado a contextos de mayor proximidad (Lorenzo Díaz, 2016; Querol Bataller, 2016; Sampedro Mella, 2019). Los ejemplos documentados en este trabajo corresponden a situaciones en las que la utilización del imperativo no representa per se una fuerte amenaza para el receptor de la petición. Así, este modo verbal se emplea para realizar peticiones de bajo coste o nivel impositivo $\mathrm{y}$, en función de las circunstancias contextuales y de la relación entre los hablantes, se acompaña de justificaciones.

Además de la expresión mediante el imperativo, se han identificado otros procedimientos directivos, como el uso de verbos volitivos en primera persona en secuencias enunciativas afirmativas:

(10) y le dices oye quiero que me agrandes este-/ este anillo// tal/ dos números (PRESEEA-Alcalá prim. E. 38).

(11) llamando por teléfono jeh! quiero que me mandes un kilo de carne/ no sé qué/ no sé cuántos/ ni sé menos (CSCP med. E. 31).

(12) como se pedía en aquel entonces quiero que seas la madre de mis hijos (CSCP sup. E. 65). 
La expresión de la petición mediante este tipo de formas verbales volitivas en primera persona aparece de manera más restringida en la muestra estudiada, ya que solo se han encontrado ejemplos en contextos transaccionales (10 y 11), con la excepción de (12). Estos enunciados aparecen expresados exclusivamente en presente de indicativo, lo que podría conllevar una amenaza potencial para el interlocutor. Ahora bien, al igual que ocurre con el uso del imperativo, pese a que su formulación parezca impositiva, no implica una amenaza para la imagen de ninguno de los participantes, por tratarse de peticiones relacionadas con la labor profesional del interlocutor: pedirle a un joyero que agrande un anillo (10) o encargarle un pedido a un carnicero (11).

En los contextos familiares se ha documentado un único caso expresado mediante una forma volitiva (12): una petición matrimonial. Por sus condiciones de realización, este enunciado no contiene la misma fuerza ilocutiva que los restantes, pues, aunque los recursos lingüísticos sean los mismos, las circunstancias en las que se manifiesta el acto comunicativo no admiten una interpretación impositiva. Así, hay que tener en cuenta, como indica Schrott (2017, p. 194) que "la selección de una u otra estructura idiomática para realizar una petición -sea la interrogación directiva, sea un imperativo- no depende exclusivamente de la comunidad cultural sino también del contexto social [...]”.

Por último, los ejemplos (13) a (16), presentan una expresión realizativa (performative) (Blum-Kulka, 1989). Están formados por secuencias afirmativas sin atenuadores, que constituyen turnos iniciativos:

(13) le digo ahí te queda el vaso/ me abres una botella/ y te pago la botella entera (ESLORA med.SCOM_H32_032)

(14) de repente escuchabas jazafata/le pedí un agua cuando salimos de Barcelona y aún no me la trajo! (ESLORA sup. SCOM_M13_010)

(15) le dije digo si viene: $A$ le dices que estoy en la peluquería (PRESEEA-Alcalá prim. E. 48)

(16) me re mandaba a un recado a// a las Huérfanas// ¿no? al s cuando/ al salir del colegio te pasas por no sé qué y me traes unas cremalleras (ESLORA sup. SCOM_H23_006)

Los enunciados (13) y (14), aun sin contener formas lingüísticas como el imperativo, se asemejan a actos más directivos que la petición, como la orden o, incluso, el reproche, que los vistos en (1) a (9), en la medida en que su formulación resulta impositiva por el contenido que transmiten, que refleja la insatisfacción del hablante por la actuación profesional del receptor: en (13) el camarero le ha servido el vino de una botella ya abierta y en (14) la azafata no ha traído aún la bebida. Este último ejemplo podría incluso interpretarse como una petición indirecta; aunque 
se trata de un mecanismo que permite realizar el acto de petición de manera encubierta, razón por la que se considera una estrategia de atenuación muy marcada (cf. Brown y Levinson, 1987; Calsamiglia y Tusón, 2007; Escandell Vidal, 2006; Haverkate, 1994), en este caso su función discursiva es justo la contraria: conseguir el objeto de la petición, un vaso de agua, a través del reproche. En cambio, el grado de imposición de la expresión 'realizativa' en la esfera familiar (15 y 16) es mucho menor que en la esfera pública y, de hecho, este tipo de construcciones es relativamente frecuente en el ámbito doméstico.

El empleo de formulaciones consideradas impositivas, como las que hemos visto a lo largo de este apartado, en la realización de las peticiones implica que los hablantes no las perciben negativamente, ya que las utilizan sin reservas en la reproducción de este acto de habla en la entrevista semidirigida. Esto indica que no parecen sentir amenazada su imagen de afiliación (Bravo, 1999, 2008; Hernández Flores, 1999, 2006) por emplear este tipo de expresiones; antes al contrario: su uso es superior al de los procedimientos indirectos.

Por otro lado, no se documentan diferencias considerables entre las peticiones realizadas mediante estrategias directas en el entorno familiar o en el transaccional. La variación más destacable es que, en el primer caso, las peticiones pueden ir acompañadas de justificaciones que funcionan como atenuadores, mientras que, en los intercambios transaccionales, se expresan de una manera más directa, sin circunloquios. Sin embargo, esto no parece estar relacionado con el contexto de producción de las peticiones, sino con la finalidad comunicativa del acto: las peticiones realizadas en situaciones familiares tienen como fin conseguir algún tipo de provecho por parte del destinatario (que haga la cama, que llame por teléfono, que mueva el coche...), si bien en las transaccionales, el objetivo es la compra de un producto (v.g., gasolina, una barra de pan, un kilo de carne, etc.), sin obtener a cambio una ganancia del receptor-vendedor. Por tanto, las condiciones de realización de la petición, la relación entre los interlocutores y el coste que implica el acto, junto con el hecho de que el beneficio recaiga solo sobre el emisor, parecen influir en la elección de ciertas estrategias de cortesía, como las justificaciones.

En lo referente a los contextos transaccionales, cabe mencionar que los enunciados de este apartado evidencian que los hablantes no consideran estos intercambios como situaciones de formalidad, de imposición o de posible amenaza que requieran mantener una mayor distancia comunicativa con respecto al interlocutor, aunque los participantes no se conozcan. Así, en España, como en otras “culturas de acercamiento" (Albelda y Briz, 2010; Grupo CRIT 2003, 2006), las transacciones cotidianas (compras en una panadería, un bar, una carnicería, etc.) no conllevan, a priori, una amenaza implícita para ninguno de los participantes (cf. Hernández López y Placencia, 2004). Por este motivo, los emisores-compradores interactúan con los receptores-vendedores de un modo cercano, emplean 
expresiones directas sin marcas de atenuación y el tuteo como forma de tratamiento generalizada. Estos recursos, propios de la cortesía positiva, serían considerados como una amenaza contra la imagen negativa del receptor en las culturas de distanciamiento, desde la perspectiva de Brown y Levinson (1987). No obstante, en el contexto español, la confianza se percibe positivamente y su ausencia se evalúa de manera negativa, incluso cuando los participantes no se conocen; por tanto, el empleo de estos recursos permite a los hablantes construir una imagen afiliativa acorde a las condiciones de su cultura (cf. Bravo, 2008, p. 587).

\subsection{La petición indirecta: de la convencional a la no convencional}

Briz (1998) y Albelda (2010) distinguen dos tipos de atenuación: la atenuación de lo dicho, que está relacionada con la forma del contenido proposicional y se manifiesta a través de la selección de recursos léxicos (eufemismos, lítotes) o morfológicos (como diminutivos), y la atenuación del decir, que se sitúa en el nivel de la fuerza ilocutiva de la petición, permitiendo rebajarla. Para ello, se pueden emplear formas verbales en distintos tiempos (pretérito imperfecto, condicional, etc.) $\mathrm{u}$ otros procedimientos de distanciamiento, como oraciones condicionales, perífrasis modalizadas, interrogativas directivas (Escandell Vidal, 1999), etc. En la muestra analizada se han hallado casos en los que la atenuación se presenta en el nivel del decir, como en los siguientes ejemplos (17-21), formulados mediante oraciones interrogativas directas y con marcas adicionales de atenuación en algunos de ellos:

(17) vas a la farmacia/ le pides al farmacéutico es que me duele esto/ ¿qué me das? (CSCP med. E. 27)

(18) y mi madre le dijo oiga/ me puede poner el compac $<\mathrm{sic}>$ de Compai ${ }^{7}$ (CSCP med. E. 39)

(19) y y y yo mama ¿traes pan? (PRESEEA-Alcalá prim. E. 53)

(20) (...) ¿oye me das un cigarro? (PRESEEA-Alcalá med. E. 29)

(21) siempre te decían oye ¿te importa si fumo? (ESLORA sup. SCOM_H13_013)

Algunos autores como Alba de Diego (1994), Haverkate (1994) o Escandell Vidal (2006) consideran que la interrogativa forma parte de los procedimientos indirectos por la libertad de actuación que confiere al receptor. En los contextos

$7 \mathrm{El}<$ sic $>$ es nuestro y, aunque en el corpus se ha transcrito sin signos de interrogación, el contenido invita a pensar que se trata de una secuencia interrogativa y no afirmativa. 
transaccionales, las interrogativas, aun sin más recursos de atenuación, permiten suavizar la imposición del acto en sí mismo (¿me pones una cerveza? vs. po(n)me treinta euros), pero el principio de libertad de actuación del destinatario no resulta operativo. Esto se debe a que no se trata de preguntas encaminadas a influir en el interlocutor para que realice una acción en beneficio del emisor, sino que tienen como objetivo la compra de un producto.

En el caso de (17), el acto tiene lugar en una farmacia y se acompaña de una justificación que precede a la petición, y en (18) sorprende el uso de la perífrasis con el verbo poder, pues apenas se han documentado modalizaciones con este tipo de perífrasis en los corpus analizados. Por tanto, estos resultados se oponen de nuevo a los de otras investigaciones (Lorenzo Díaz, 2016; Querol Bataller, 2016; Sampedro Mella, 2019) en las que se observa un mayor empleo de los procedimientos de atenuación en la expresión de la petición en el español peninsular, en especial mediante las perífrasis con "poder" en distintos tiempos verbales.

En cuanto a las situaciones familiares, si bien el uso de interrogativas directas es mucho menor, las interrogativas con elementos atenuadores son el segundo recurso más empleado en la realización de las peticiones por detrás del imperativo. Así, una secuencia como (19), formulada de una hija a su madre, por implicar una petición de bajo coste no necesita acompañarse, a priori, de otro tipo de estrategias de mitigación. Por el contrario, las peticiones (20) y (21), cuyo objetivo es poder fumar en presencia del receptor o pedirle un cigarrillo, sí precisan de elementos corteses adicionales para conseguir el objeto de la petición sin amenazar la imagen social del interlocutor, aunque sea una persona con la que se mantiene una relación más próxima. En estas situaciones, además de la interrogativa, los hablantes emplean otras estrategias discursivas, como imperativos lexicalizados que funcionan como marcadores de apertura (oye) o procedimientos acompañantes (me das, te importa) que distancian al emisor del contenido enunciado.

En la línea de la atenuación, compárense los ejemplos expuestos en (13) a (16) con los siguientes (22 a 25), en los que, a pesar de tratarse igualmente de secuencias afirmativas, encontramos distintos elementos mitigadores que rebajan la fuerza impositiva de las peticiones que introducen:

(22) y recibir a la gente que le vencía/ oyes mira a ver si:/ (e:) me puedes subir medio punto porque me han dicho que en el banco// no sé (PRESEEA-Alcalá med. E. 31)

(23) Óscar le dijo mira yo es que tengo esta idea y no sé qué yo quisiera hablar contigo (PRESEEA-Alcalá sup. E. 15)

(24) le dijimos a mi hermana oye mira $\mathrm{mm} \mathrm{mm} /$ eeh vas a tener que venir a buscar a la niña porque echa muchísimo de menos a sus padres (ESLORA med. SCOM_M32_023) 
(25) se me ocurrió decirle a mi madre mire/mamá/veo que yo el día de mañana no voy a tener ningún oficio ni ningún beneficio/ (...) pues mira/ mamá/ me gustaría ser/ por lo menos/ mecánico (CSCP prim. E. 16)

Las peticiones en contextos transaccionales (22 y 23), expresadas a través de secuencias enunciativas afirmativas que incluyen marcas de atenuación, conllevan un mayor coste-beneficio: la negociación de un préstamo hipotecario (22) o una propuesta de obra a un arquitecto (23). En estos casos, el emisor-cliente se encuentra en una situación más arriesgada, pues necesita la intervención del destinatario para conseguir su propósito. Con este fin, y para evitar la posible amenaza a la imagen de afiliación y de autonomía del receptor, y a su propia imagen afiliativa, los hablantes emplean distintas estrategias, como imperativos lexicalizados (mira, oye) y marcadores discursivos que funcionan como circunloquios, dando lugar a secuencias explícitas de apertura (mira yo es que; oyes mira a ver si) que introducen la petición de una manera más encubierta.

Lo mismo sucede en las peticiones realizadas en el ámbito familiar, en las que el incremento en el número de estrategias de atenuación se relaciona también con el mayor nivel impositivo de la petición: recoger a la hija de la casa de unos familiares por los problemas de adaptación que está teniendo (24) o iniciar una profesión cuando la situación económica familiar no lo permite (25). Encontramos en estos enunciados interjecciones que expresan duda $(\mathrm{mm} \mathrm{mm} /$ eeh) y otros procedimientos distanciadores, como circunloquios (vas a tener que, veo que yo el día de mañana), imperativos lexicalizados que funcionan como marcadores (oye mira), el condicional (me gustaría ser) o justificaciones con hipérboles antes o después del enunciado, que hacen que las secuencias resulten más corteses: porque echa muchísimo de menos; no voy a tener ningún oficio ni ningún beneficio.

Además de las peticiones formuladas mediante procedimientos indirectos para atenuar su expresión, encontramos las denominadas indirectas no convencionales (Blum-Kulka, 1989; Félix-Brasdefer, 2005; Escandell Vidal, 2006), que dan lugar a "actos de habla indirectos" (Searle, 1969). Esta clase de peticiones indirectas puede manifestarse mediante secuencias afirmativas (26, 27 y 30) o interrogativas (28 y 29), en las que el hablante expresa de manera literal una idea con la intención de que sea reinterpretada como una petición por parte del receptor:

(26) digo pues mira que se ha ido la luz (PRESEEA-Alcalá sup. E. 5)

(27) y le dijimos mira nos acaba de pasar esto (ESLORA med. SCOM_M22_029)

(28) una amiga me dijo Óscar/ ¿que tú sabes algo francés? (CSCP med. E. 39)

(29) hasta con mi madre (...) ;aay!/ ¿te vas a dejar la bici ahí?/ iyy mira que si te la roban! (VAL02111HC06)

(30) el otro día me decía es que no me hablas en valenciano (VAL02411MB06) 
Las peticiones de (26) y (27) tienen lugar en contextos transaccionales y se emplean para informar de la falta de luz en la vivienda (26) y de un incidente en un viaje, ajeno al establecimiento, en la recepción de un hotel (27). Este tipo de peticiones no es habitual en las transacciones, debido, una vez más, a la finalidad del acto en este tipo de intercambios: realizar una compra. Estos dos ejemplos reproducen peticiones cuya finalidad es conseguir resolver un problema a través de la intervención de los receptores, por lo que la utilización de una formulación indirecta permite advertir de lo sucedido con el propósito no manifiesto de que el destinatario tome la iniciativa de ayudar al hablante.

Los restantes enunciados tienen lugar en la esfera privada: en el ejemplo (28), la pregunta la realiza una joven a su amigo del que sabe que efectivamente habla francés, para pedirle que se comunique en esta lengua con unos interlocutores no hispanohablantes. En (29), una madre le pregunta a su hijo si va a dejar ahí la bicicleta y señala el peligro que corre en ese lugar (jyy mira que si te la roban!), con la intención de pedirle de manera indirecta que no la deje en la calle. Finalmente, en (30), el hablante se queja a su novia de que no le habla en valenciano, con el fin de que se dirija a él en esa lengua que, a su juicio, se está perdiendo.

Los resultados del análisis de nuevo muestran que apenas existen variaciones entre el ámbito público y el privado en la expresión de las peticiones. En cuanto a los intercambios transaccionales, aunque la mayoría de los enunciados presentados en este trabajo corresponde a situaciones informales en distintos comercios (una joyería, panadería, bar, gasolinera, etc.), no se aprecia, en los datos examinados, una conexión entre el nivel de cortesía mitigadora empleada en los enunciados y su contexto de producción, pero sí en relación con el objeto de la petición y el coste-beneficio de su realización: cuando se trata de peticiones pequeñas o de la adquisición de productos cotidianos que no requieren una intervención adicional por parte del receptor-vendedor se expresan de forma directa, mediante imperativos, secuencias afirmativas, verbos volitivos, etc.; sin embargo, cuando el emisor intenta realizar una transacción más importante o se enfrenta a un problema y espera una posible solución por parte del interlocutor, la formulación tiende a ser más distante y cortés, pero no hay una reducción de las estrategias de cercanía con el receptor. En otras palabras, encontramos un distanciamiento en relación con el objeto, pero no con el interlocutor, pues los hablantes, en este tipo de contextos, no perciben una amenaza potencial en el trato que requiera marcar distancia comunicativa (Hernández López y Placencia, 2004), sino que procuran mantener la cercanía y construir de esta manera su imagen afiliativa (Bravo, 1999, 2008; Hernández Flores, 1999, 2006), según las condiciones de la cultura a la que pertenecen. Finalmente, de las dos clases de atenuación posibles identificadas por Briz (1998) y Albelda (2010), a saber, de lo dicho y del decir, solo se han registrado muestras de este último tipo. 


\section{4 ¿Petición u ofrecimiento?}

En la recopilación del subcorpus de peticiones formuladas en contextos familiares, se han hallado algunos enunciados en los que podemos comprobar que los límites entre la petición y otros actos de habla directivos, como el ofrecimiento o la invitación, ${ }^{8}$ no son del todo claros. Veamos algunos ejemplos:

(31) y me vio y dice oye/por qué no te vienes a Barcelona (CSCP med. E. 45)

(32) y dijo oye M. ¿por qué no nos vamos a comer por ahí? (CSCP med. E. 45)

(33) y allí pues dice ¿por qué no te animas a ir a la misa? (ESLORA sup. SCOM_H33_015)

En estos enunciados, el acto se expresa mediante secuencias interrogativas negativas con estrategias que conllevan mayor distanciamiento con el objeto de la petición que las que aparecen en los ejemplos (17) a (21), como la partícula interrogativa por qué, que invierte el papel de la petición haciendo que se aproxime a una invitación, a pesar de que supongan dos acciones contrarias. En efecto, Escandell Vidal (1999) señala que las interrogativas encabezadas por la locución adverbial ¿por qué...? presentan un comportamiento especial, ya que están sujetas a distintas interpretaciones, como la invitación o la sugerencia (¿por qué no vienes a la fiesta?), o la orden (¿por qué no recoges la mesa?). Por tanto, son los factores pragmáticos, como la relación entre los participantes o el contenido preposicional, y no su expresión, los indicadores del acto que introducen.

En estos enunciados, por tratarse de secuencias reproducidas en estilo directo, carecemos de un contexto amplio para poder determinar con precisión el tipo de acto que introducen. Los ejemplos (31) y (32) pueden interpretarse como una invitación al receptor a visitar al emisor en Barcelona (31) o como una sugerencia a comer fuera, por involucrar tanto al emisor como al receptor (32). El enunciado (33) parece recibir, en cambio, una interpretación directiva, propia de las peticiones, por tratarse de una proposición de una tía a su sobrino, todavía niño, para acudir a una misa. Marsily (2018), siguiendo la ordenación de Blum-Kulka (1989), considera que estos ejemplos constituyen un subtipo de peticiones indirectas convencionales, formadas por preguntas sobre la capacidad o la voluntad del interlocutor para llevar a cabo la acción. En su estudio, basado en peticiones naturalizadas,

8 En ocasiones, debido a su dimensión comisiva, el ofrecimiento puede confundirse con la invitación. Si bien ambos actos se orientan a una situación futura, la diferencia entre ellos es que el primero consiste en una acción que el hablante propone realizar en beneficio del interlocutor (¿te preparo un café?), mientras que la invitación, aun siendo también un acto que parte del emisor y beneficia al receptor, requiere la acción de este último para que se pueda llevar a cabo (¿quieres tomar un café?) (Ruiz de Zarobe, 2000). 
encuentra que es un recurso muy poco habitual a la hora de realizar las peticiones por hablantes no nativos de español, lo que puede obedecer al carácter difuso entre la petición y otros actos de estas secuencias y, consecuentemente, a su difícil asimilación por parte de los aprendices del idioma.

También, entre la petición y el ofrecimiento, encontramos los siguientes ejemplos: ${ }^{9}$

(34) pues mi abuelo les dijo juy! dejadnos a la nena que nos hace mucha compañía y tal (VAL02211MB06)

(35) (...) Venid/ que hoy da una clase L. sobre/ sobre el Lazarillo (CHCS, E. 11)

(36) y como vecinos pues todo el mundo (...) bájate a sentarte aquí bájate va (PRESEEA-Alcalá prim., E. 53)

(37) mi madre llamó a mi tía pues he comprado un edredón/ pasa a verlo (PRESEEA-Alcalá sup., E. 3)

Los ejemplos de (34) a (37), expresados mediante imperativos, resultan ambiguos, pues atendiendo a su formulación podrían ser peticiones, pero por su contenido proposicional parecen más bien ofrecimientos. Este hecho resulta sorprendente teniendo en cuenta que, aunque pedir y ofrecer son actos de habla directivos (Searle, 1969) por requerir la acción del interlocutor para su ejecución, suponen dos acciones contrapuestas. Estos enunciados discursivamente ambiguos tienen en común que se construyen con verbos que implican un movimiento (dejar, venir, bajar, pasar) y en imperativo, por lo que en una misma secuencia se une la fuerza ilocutiva de este modo verbal con la opcionalidad del enunciado: la posibilidad de dejar a la niña (34), de asistir a una clase (35), de desplazarse hasta el lugar indicado (36) o de acudir al domicilio de la hermana a ver el edredón (37).

Para poder determinar el acto de habla en estos ejemplos, debemos recordar que la petición, en intercambios no transaccionales, es un acto en el que el emisor solicita una acción del receptor, cuyo beneficio recae sobre el propio emisor, mientras que el ofrecimiento es un acto en el que el hablante realiza una acción en beneficio del interlocutor. En palabras de Escandell Vidal (1999, pp. 3976-3977): “Las 'peticiones' se sitúan en el extremo más alto de una escala que contempla el beneficio que le reporta al emisor el cumplimiento de la acción solicitada. En el otro extremo se sitúan los 'ofrecimientos', que están centrados en la realización de una acción cuyos beneficios deberían repercutir en la persona misma que la realiza”.

9 Enunciados como los expuestos en los ejemplos (34) a (39) se han excluido de las clasificaciones cuantitativas presentadas en 4.1., dada la imposibilidad de confirmar si se trata efectivamente de peticiones o de otros actos por la ausencia de un mayor contexto. 
Los límites teóricos de ambos actos parecen quedar manifiestamente claros y, sin embargo, en enunciados de estas características no siempre se perciben con la misma nitidez: en (34) los abuelos demandan la presencia de la nieta en su domicilio, lo que se puede interpretar como un ofrecimiento de ayuda a los padres, o bien como una petición, ya que les hace mucha compañia; en (35) parece tratarse de una invitación a presenciar una clase que será de interés para los receptores, con lo cual el beneficio recaería sobre ellos, pero al mismo tiempo sobre el emisorinvitador por recibir la compañía de sus amigos; (36) comprende también una invitación entre vecinos, por lo que el beneficio, por la compañía, se presupone igualmente mutuo; por último, en (37) es donde mejor se percibe que estaríamos ante una invitación, porque, si bien el beneficio del acto sería para la emisora, en tanto que vería satisfecha su imagen positiva al poder compartir su recién adquirido edredón, también lo es para la receptora por la complicidad que le brinda su hermana. En una línea similar se encuentran enunciados exhortativos como los siguientes:

(38) (...) pues mira/ podemos ir en coche hasta tal sitio (CSCP med., E. 35)

(39) yo le decía yo el de Boiro <vacilación/> oye pero a ver ijoder! un día de estos tenemos que ir a tenemos que ir a la lubina (ESLORA med., SCOM_H12_027)

Aunque se trata de actos que normalmente se interpretan como invitaciones $u$ ofrecimientos, la formulación exhortativa evoca a la naturaleza de las peticiones; además, presentan un carácter ambivalente, pues el beneficio de su realización parece recaer sobre el emisor y el receptor. Por todo ello, estos enunciados ponen de manifiesto que los límites teóricos de un acto de habla como la petición en ocasiones pueden desdibujarse, por la incorporación de elementos propios de otros actos en su expresión o porque no se aprecia con nitidez quién es el locutor que se beneficia del objeto del acto. Este tipo de expresión ambigua (38 y 39), en la que se involucra al emisor y al receptor con el contenido de la acción, permite a los hablantes reforzar los lazos y proyectar una imagen afiliativa basada en la confianza mutua por la realización de una acción en común. Por consiguiente, una formulación de estas características no parece tener cabida para adquirir un producto en un establecimiento, razón por la que estas construcciones no se documentan en las muestras de peticiones en intercambios transaccionales.

\section{Conclusiones}

Esta investigación sobre los procedimientos pragmalingüísticos empleados en la expresión de la petición en contextos transaccionales y de proximidad social se ha 
basado en el análisis de muestras textuales reproducidas en estilo directo en entrevistas semidirigidas. Se trata de un género más formal que la conversación espontánea (cf. Fernández Sanmartín et al., 2008), pues, por lo general, los participantes no se conocen de antemano y el encuentro se graba con la autorización del entrevistado. Todo ello hacía prever que pudieran aparecer variaciones en la expresión del acto de la petición en su reproducción a través del discurso directo. En efecto, se esperaba que los hablantes adaptaran el mensaje original al nuevo contexto comunicativo, a fin de construir una imagen de afiliación (Bravo, 1999, 2008; Hernández Flores, 1999, 2006) satisfactoria y acorde a las características de la entrevista semidirigida, a través de un aumento de las estrategias de atenuación y distanciamiento cortés, o un lenguaje más cuidado que en la enunciación original.

No obstante, en la muestra analizada encontramos un lenguaje coloquial y un incremento de los procedimientos directivos. Aunque no contamos con las peticiones formuladas originalmente para detectar las posibles modificaciones en su paso al estilo directo, destaca el empleo de este tipo recursos que también registran algunos trabajos previos sobre la petición (Haverkate, 1994; Siebold, 2006), pero no las investigaciones basadas en la metodología DCT (Lorenzo Díaz, 2016; Querol Bataller, 2016; Sampedro Mella, 2019). Este resultado es similar al obtenido por Hernández Flores (2002) en un estudio en el que compara los procedimientos utilizados en varios actos en conversaciones reales y en cuestionarios, y observa un mayor empleo de estrategias indirectas en la expresión de la petición en los cuestionarios que en las muestras orales.

En los ejemplos examinados en este trabajo se documentan formas que pueden considerarse impositivas, como el imperativo, pero, por no aparecer en contextos en los que su empleo represente una imposición para el receptor, no se interpretarían de tal manera. Por otro lado, algunas de las peticiones formuladas mediante una secuencia afirmativa podrían ser percibidas como una orden o un reproche. Por tanto, la atribución de significados directivos o atenuados a ciertas estructuras lingüísticas no debe relacionarse únicamente con la propia expresión del acto, ya que, de acuerdo con Escandell Vidal (1999) y Schrott (2017), el nivel de fuerza ilocutiva de la petición no deriva de las propiedades estructurales del enunciado, sino que depende decisivamente del propio contenido proposicional y de las condiciones que rodean a su enunciación. En palabras de Hernández Flores (2006, p. 39): "no hay actos corteses o descorteses, sino que el significado social del acto o los actos depende de cada situación y de lo que dicta el marco cultural para esa situación”.

La petición en el ámbito familiar y en el transaccional se diferencia desde su propio planteamiento como acto de habla, pues en el primer caso se realiza con el objetivo de obtener un beneficio por parte del interlocutor, mientras que en el 
segundo tiene como fin la compra de un producto. A pesar de estas diferencias, las estrategias identificadas para la expresión de la petición son similares en ambos contextos, con algunas pequeñas variaciones: las peticiones indirectas apenas se registran en las transacciones, tal y como era esperable, y la formulación mediante la forma volitiva quiero solo aparece en las transacciones, posiblemente porque podría ser interpretada como demasiado impositiva $u$ orientada al yo en otro tipo de situaciones.

Con respecto a las estrategias pragmalingüísticas documentadas, no parece haber diferencias vinculadas al tipo de contexto, sino al coste-beneficio del objeto de la petición. Así, en las peticiones con mayor coste o que requieren una gran intervención por parte del receptor encontramos más elementos mitigadores, procedimientos acompañantes o justificaciones. Ahora bien, es importante señalar que este incremento en las estrategias de atenuación se orienta al objeto de la petición, no al interlocutor, ya que aun en los casos en los que la expresión contiene un mayor número de recursos de atenuación, los hablantes no marcan distancia con el receptor, sino que utilizan estrategias valorizantes para dirigirse a él. Este hecho tiene que ver con la estimación del nivel de confianza (Bravo, 1999; Hernández Flores, 1999, 2002, 2006) que existe entre los locutores en dichas situaciones dentro de la cultura española, pues la cercanía se percibe como un atributo positivo y, por ello, se mantiene en todas las situaciones, con independencia del contenido o del coste de la petición.

Por último, cabe mencionar que esta investigación ofrece una aproximación al estudio de la petición en un contexto novedoso: el discurso directo reproducido en la entrevista semidirigida. El análisis de este tipo de muestras aporta un nuevo enfoque al campo de estudio del estilo directo (en el cual las investigaciones suelen estar centradas en aspectos formales de la construcción, pero no en el contenido expresado por la cita), y supone también un primer acercamiento al estudio pragmático de los actos de habla en este contexto. Aunque esta aproximación presenta algunas limitaciones, como la falta del discurso original para identificar posibles variaciones en su paso al estilo directo, los resultados permiten aportar ciertas hipótesis acerca de la expresión de la petición, y parecen indicar que este medio puede ser adecuado para el análisis de fenómenos pragmáticos o discursivos, ante las dificultades existentes para recopilar muestras de lengua espontáneas de algunos actos de habla, en especial en contextos transaccionales.

Agradecimientos: Este trabajo forma parte de los proyectos "Pragmática intercultural de los actos de habla recíprocos, petición y ofrecimiento, en diferentes lenguas y variedades" y "Comunicación y adecuación pragmalingüística: cortesía, actos de habla y deíxis social”, para los que he contado con una beca posdoctoral de la Xunta de Galicia (referencia ED481B 2018/036). 


\section{Referencias}

Alba de Diego, V. (1994). La cortesía en las peticiones. En Sánchez Lobato, J. y Santos Gargallo, I. (Eds.), Actas del IV Congreso Internacional de ASELE (pp. 413-425). Madrid: SGEL.

Albelda, M. (2010). ¿Cómo se reconoce la atenuación? Una aproximación metodológica basada en el español peninsular hablado. En Orletti, F. y Mariottini, L. (Eds.), (Des)cortesía en español (pp. 41-70). Roma: Università Roma Tre.

Albelda, M., y Briz, A. (2010). Aspectos pragmáticos. Cortesía y atenuantes verbales en las dos orillas a través de muestras orales. En Aleza Izquierdo, M., La lengua española en América: normas y usos actuales (pp. 237-269). València: Universitat de Vàlencia.

Blas Arroyo, J. L., Navarro Morales, B., y Casañ Núñez, J. C. (2009). Corpus sociolingüístico de Castellón de la Plana y su área metropolitana. Castelló de la Plana: Universitat Jaume I. (Citado como CSCP sup., med., prim.).

Blum-Kulka, S. (1989). Cross-cultural and situational variation in requesting behavior. En Blum-Kulka, S., House, J., y Kasper, G. (Eds.), Cross-cultural pragmatics: requests and apologies (pp. 123-154). NY: Ablex Publishing Corporation.

Bravo, D. (1999). ¿Imagen positiva vs. imagen negativa? Pragmática socio-cultural y componentes de face. Oralia, 2, 155-184.

Bravo, D. (2008). The implications of studying politeness in Spanish speaking contexts: a discussion. Pragmatics, 18(4), 577-603.

Briz, A. (1998). El español coloquial en la conversación. Esbozo de pragmagramática. Barcelona: Ariel.

Brown, P., y Levinson, S. (1987). Politeness: Some universals in language usage. Cambridge: CUP.

Calsamiglia, H., y Tusón, A. (2007). Las cosas del decir: Manual de análisis del discurso. Barcelona: Ariel.

Escandell Vidal, M. V. (1999). Los enunciados interrogativos. Aspectos semánticos y pragmáticos. En Bosque, I. y Demonte, V. (Eds.), Gramática descriptiva de la lengua española (pp. 3931-3991). Madrid: Espasa Libros.

Escandell Vidal, M. V. (2006). Introducción a la pragmática. Barcelona: Ariel.

Estévez-Rionegro, N. (2017). Las construcciones de estilo directo en español. Estudio de corpus. Tesis doctoral inédita. Santiago de Compostela: USC.

Félix-Brasdefer, J. C., (2005). Indirectness and politeness in Mexican requests. In: Eddington, D. (Ed.), Selected proceedings of the 7th hispanic linguistic. symposium (pp. 66-78). Cascadilla Press, MA, Somerville.

Fernández Juncal, C. (2005). Corpus de habla culta de Salamanca. Burgos. Instituto Castellano y Leonés de la Lengua (Citado como CHCS).

Fernández Sanmartín, A., García Salido, M., Recalde, M., \& y Vázquez Rozas, V. (2008). Reflexiones metodológicas sobre la técnica de la entrevista semidirigida. Actas del XV Congreso Internacional de ALFAL. Montevideo, Uruguay. Recuperado de. Retrieved from http:// gramatica.usc.es/ vvazq/pdf_publ/entrevista_semidir_alfal_2008.pdf.

Gallucci, M. J. (2012). Estilo directo e indirecto en interacciones orales. Estado de la cuestión en el ámbito hispánico. Boletín de Filología de la Universidad de Chile, 47(2), 205-233.

Goffman, E. (1967). Ritual de la interacción. Buenos Aires: Tiempo Contemporáneo.

Gómez Molina, J. R. (2007). El español hablado en Valencia Materiales para su estudio. III Nivel sociocultural bajo. Anejo XLVI de Cuadernos de Filología. València: Universitat de València (Citado con los códigos cada entrevista). 
Grupo, C. R. I. T. (2003). Claves para la comunicación intercultural. Castelló: Universitat Jaume I.

Grupo, C. R. I. T. (2006). Culturas cara a cara: Relatos y actividades para la comunicación intercultural. Madrid: Edinumen.

Haverkate, H. (1994). La cortesía verbal. Estudio pragmalingüístico. Madrid: Gredos.

Hernández Flores, N. (1999). Politeness ideology in Spanish colloquial conversation: The case of advice. Pragmatics, 9, 37-49.

Hernández Flores, N. (2002). Los test de hábitos sociales y su uso en el estudio de la cortesía. Una introducción. En Bravo, D. (Ed.), Actas del primer coloquio del programa EDICE (pp. 186-197). Estocolmo: Universidad de Estocolmo.

Hernández Flores, N. (2006). Cortesía y oscilación de la imagen social en un debate televisivo. En Murillo Medrano, J. (Ed.), Actas del segundo coloquio del programa EDICE (pp. 37-54). Estocolmo: Universidad de Estocolmo.

Hernández López, M., y Placencia, M. E. (2004). Modos de conducir las relaciones interpersonales en interacciones de atención al público: el caso de las farmacias en Sevilla y Londres. ELUA, $18,119-150$.

Labov, W. (1966). Principles of the linguistic change. Oxford: Blackwell.

Lorenzo Díaz, I. (2016). Realizaciones, conciencia y enseñanza-aprendizaje del acto de habla de la petición en educación secundaria. Tesis doctoral. Madrid: Universidad Complutense de Madrid.

Maldonado González, C. (1991). Discurso directo y discurso indirecto. Madrid: Taurus.

Marsily, A. (2018). “¿Es normal que sea un poco difícil de leer la consigna?” La atenuación en las peticiones de hablantes no nativos de español. ELUA, Anexo, 4, 251-268 Recuperado de.

Méndez García de Paredes, E. (2000). La literalidad de la cita en los textos periodísticos. Revista Espanola de Linguistica, 30(1), 147-168.

Moreno Fernández, F., Cestero Mancera, A. M., Molina Marcos, I., y Paredes García, F. (2002). La lengua hablada en Alcalá de Henares. Hablantes de instrucción superior, media y primaria. Alcalá de Henares: Universidad de Alcalá de Henares (Citado como PRESEEA-Alcalá sup., med., prim.).

Querol Bataller, M. (2016). Estrategias, alertadores y movimientos de apoyo en las peticiones en chino y español. Pragmalinguistica, 24, 208-229.

RAE y ASALE (2009). Nueva gramática de la lengua española. Madrid: Espasa-Calpe.

Ruiz de Zarobe, L. (2000). Ofrecimiento y cortesía en francés. Vol. 14 (pp. 185-197). ELUA.

Sampedro Mella, M. (2019). Variación en la cortesía en la expresión de la petición en el español castellano y el portugués europeo. Textos en proceso, 5(1), 53-73.

Schrott, A. (2017). Cortesía verbal y competencia lingüística: La petición cortés como tradición discursiva. Normas, 7(1), 188-203.

Searle, J. (1969 [1964]). Actos de habla. Madrid: Cátedra.

Siebold, K. (2006). ¿Cómo se piden las cosas? Estudio pragmalingüístico de las peticiones en español y en alemán. En Mourón Figueroa, C. y Moralejo Gárate, T. (Eds.), Studies in contrastive linguistics (pp. 953-961). Santiago de Compostela: USC.

Vázquez Rozas, V. (IP). ESLORA: Corpus para el Estudio del Español Oral. Recurso electrónico: http://galvan.usc.es/eslora (Citado como ESLORA sup./ med.). 